\title{
LOGISTICS ASPECTS OF PETROLEUM PIPELINE OPERATIONS
}

\author{
W.J. PIENAAR \\ wpienaar@sun.ac.za \\ Department of Logistics \\ Stellenbosch University \\ South Africa
}

\begin{abstract}
The paper identifies, assesses and describes the logistics aspects of the commercial operation of petroleum pipelines. The nature of petroleum-product supply chains, in which pipelines play a role, is outlined and the types of petroleum pipeline systems are described. An outline is presented of the nature of the logistics activities of petroleum pipeline operations. The reasons for the cost efficiency of petroleum pipeline operations are given. The relative modal service effectiveness of petroleum pipeline transport, based on the most pertinent service performance measures, is offered. The segments in the petroleum-products supply chain where pipelines can play an efficient and effective role are identified.
\end{abstract}

\section{INTRODUCTION}

Transnet Pipelines is presently constructing a new $60-\mathrm{cm}$ petroleum-products pipeline $704 \mathrm{~km}$ in length from Durban to Gauteng. In addition, the Petroline consortium obtained permission to construct and operate a $30-\mathrm{cm}$ petroleum-products pipeline $160 \mathrm{~km}$ in length from Maputo to Nelspruit, to be extended later to Kendal, where it can link with the present Transnet pipeline network (Petroline, 2008). Another prospective market participant is PetroSA, which announced its intention to construct a petroleum refinery at Coega in the Eastern Cape, and to connect it with a pipeline to the interior market in South Africa (PetroSA, 2008).

In the interest of the national economy and in the commercial interest of petroleum pipeline operations, it is necessary that commercial pipeline operators provide services tailored to the need of customers at acceptable cost. Against the background of, first, the volatility in the international price of crude oil; secondly, the apparent inability to stabilise the political and economic climate in some of the largest oil-producing regions; and, thirdly, the growing demand for petroleum products in large emerging industrial countries (for example, China and India) and in large developed industrial countries (for example, the United States and Japan), it is imperative that the logistics-management aspects of petroleum-product supply chains be arranged as safely, efficiently and effectively as possible. In view of these aspects, the paper sets out to identify, assess and describe the logistics aspects of the commercial 
operation of petroleum pipelines. The research problem is threefold:

- to identify the physical characteristics of petroleum-product supply chains and to describe the logistics activities that are involved in the flow of petroleum commodities and information between place of origin and place of consumption

- to indicate the relative efficiency of pipeline operations

- to describe the criteria that exist for effective service delivery.

The Council of Supply Chain Management Professionals (CSCMP) defines logistics management as 'that part of supply-chain management that plans, implements and controls the efficient, effective forward and reverse flow and storage of goods, services and related information between the point of origin and the point consumption in order to meet customers' requirements' (Council of Supply Chain Management Professionals, 2010).

The research approach combined 1) a literature survey (which covered an identification of transport, engineering and logistics textbook material containing relevant secondary text on petroleum pipeline operations, and Internet sources that deal with pipeline operations as primary focus); 2) an analysis of the cost structure of large commercial pipeline operations; and 3) interviews conducted with specialists in the petroleum-refining and pipeline, road and rail transport industries. The author had access to confidential cost details and forecasts of the operations of existing and envisaged petroleum pipelines in South Africa. The results of these cost analyses are portrayed illustratively and described qualitatively in this paper. The consulted sources that were directly utilised in the production of this work are cited throughout the body of the paper. Parts of the text are taken from Pienaar and Vogt (2009) and Pienaar (1998; 2010a and 2010b). Examples of pipeline practice and performance in South Africa were obtained from Africon (2008), Lund (2002), Moller (2008), NERSA (2007), Pienaar (1998 and 2010a) and Pienaar and Botes (2005).

The content of the paper follows the order of the CSCMP definition of logistics management supplied above: The scope of supply chain management in terms of how it relates to petroleum pipeline operations is addressed under 'Petroleum-product supply chains' in this paper. The logistics activities in the supply chain of petroleum products involving pipeline operations, which need to be planned, implemented and controlled, are discussed in the third section ('Logistics activities'). The fourth section addresses the relative modal efficiency of pipeline transport ('Relative efficiency of pipeline operations'). The fifth section is devoted to the service effectiveness needed to meet customers' requirements ('Service effectiveness'). The conclusions of the work are contained in the sixth section. 


\section{PETROLEUM-PRODUCT SUPPLY CHAINS}

\section{Overview}

The point of origin of the supply chain of a product is where no primary suppliers exist. All suppliers to the point-of-origin members are solely supporting members. The point of consumption is where no further value is added to a product and it is consumed or used without serving as an input to another supply chain (Porter, 1984). An organisational or institutional arrangement of a product's supply chain is known as a value chain. The value chain of petroleum products is shown in the left column of Figure 1. A physical or instrumental depiction of the supply chain of petroleum products is shown on the righthand side of Figure 1.

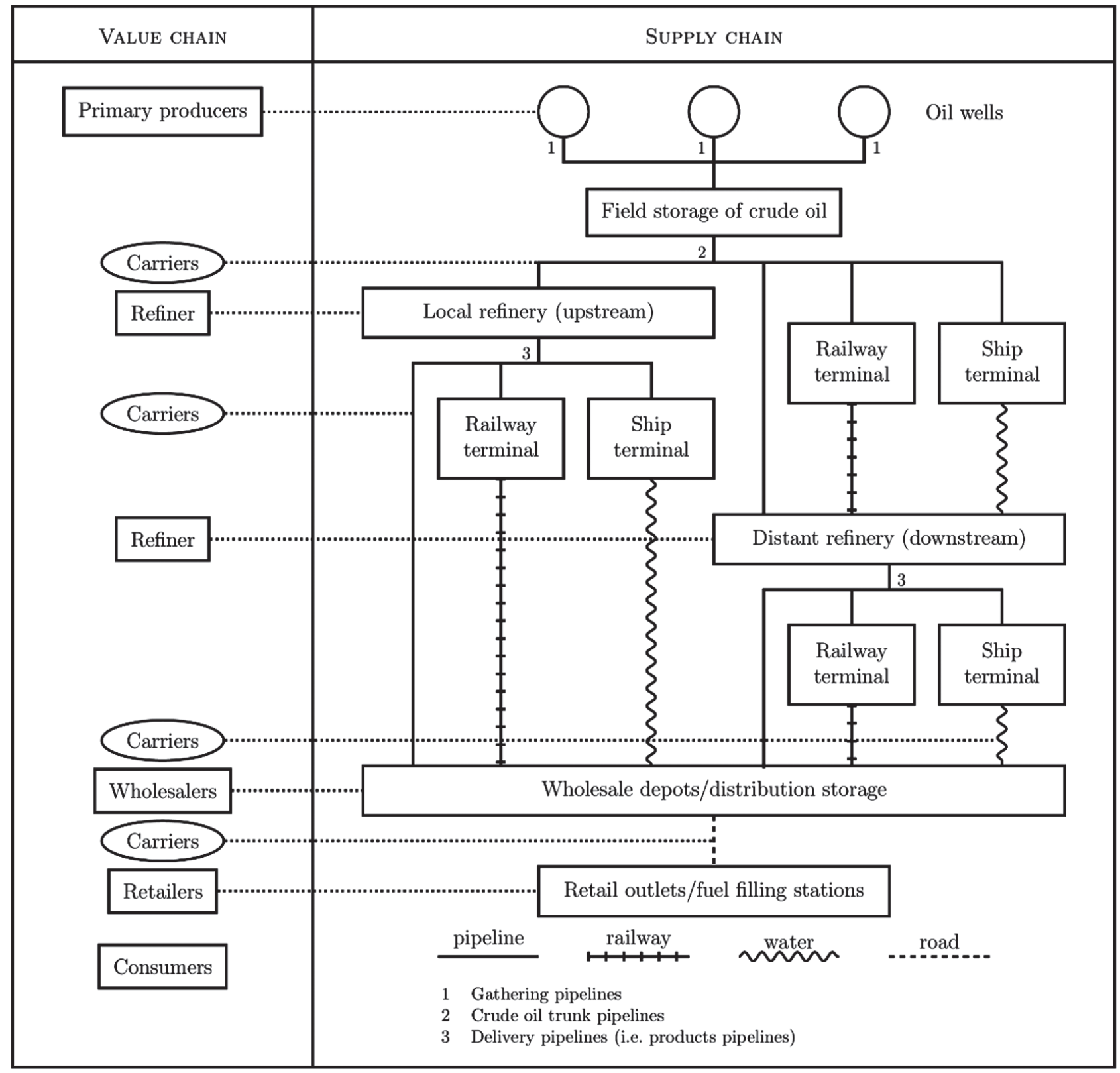

Figure 1: The value and supply chain of petroleum fuel products (Source: Pienaar \& Vogt, 2009) 
The three most important non-vegetable sources of petroleum products are crude-oil wells in production areas, natural gas fields and coal mines (the latter especially in South Africa). In Figure 1 (top right) the sources (points of origin) are indicated as oil wells in production areas. The point of consumption (bottom right, Figure 1) is taken to be where fuel consumers purchase their fuel at retail outlets (i.e. fuel filling stations).

There are three basic types of petroleum pipeline transport systems (Leonard, 1982):

1. Gathering pipeline systems

2. Crude-oil trunk pipeline systems

3. Refined-products pipeline systems

Collectively, these systems provide a continuous link between extraction, processing, distribution and wholesalers' depots in areas of consumption.

\section{Gathering pipeline systems}

As crude oil is extracted in production fields, gathering systems collect and carry it from the wells to central locations by means of a network of small-diameter low-pressure pipelines. Gathering involves a short-haul collection function, usually consolidating many streams into field storage tanks for later transfer to trunk lines (Schumer, 1974). Gathering pipelines form part of the materials management or inbound logistics portion of petroleum-product supply chains.

\section{Crude-oil trunk pipeline systems}

Crude oil is transported in trunk lines. These pipelines receive crude oil from storage tanks, gathering systems, ships, barges or other trunk pipelines. As is the case with gathering pipelines, these pipelines form part of the inbound logistics portion of petroleum-product supply chains.

A trunk line has relatively larger volumes going to relatively fewer delivery points. The delivering line has smaller shipments going to more delivery points. Generally, the trunk system operates in 'fungible' mode: the shipper receives the same quality of product that it tendered for transport, but not the same molecules, whereas the delivering line operates in 'batch' mode: the shipper receives the same molecules that it tendered for shipment (Allegro Energy Group, 2001).

\section{Refined-products pipeline systems}

Products pipelines are delivery systems that carry refined petroleum products from refineries and seaports to wholesale depots in market areas, whence the products are usually moved by truck to retail outlets and large-scale consumers. Refined-product delivery systems are a converse image of crude-oil gathering systems. Instead of small streams flowing into high-volume trunk pipelines via tank farms, products pipelines originate as large-capacity systems at tank farms at refineries, and branch into smaller-capacity pipelines to service 
dispersed delivery points - usually wholesale depots in market areas. Products pipelines form part of the physical distribution or outbound logistics portion of petroleum-product supply chains.

\section{LOGISTICS MANAGEMENT ACTIVITIES}

The following logistics management activities are involved in the flow of goods and information between place of origin and place of consumption (Ballou, 2004; Murphy \& Wood, 2004; Grant, Lambert, Stock \& Ellram, 2006; Bowersox, Closs \& Cooper, 2007; Pienaar, 2010b):

- Demand forecasting

- Facility site selection

- Procurement

- Materials-handling

- Packaging

- Warehouse management

- Inventory management

- Order processing

- Logistics communications

- Transport

- Reverse logistics

In the 11 sub-sections that follow, each of these activities is briefly described in generic terms, followed by a pipeline-specific discussion.

\section{Demand forecasting}

Logistics forecasts of demand determine how much of each product must be transported to the various markets served by the firm. It is also the function of logistics to determine where the demand will occur so that products can be made available in appropriate volumes at the right time in each market area. Knowledge of future demand levels enables logistics managers to plan the activities that will service that demand.

Before initiating a pipeline as a commercial venture, it must be shown that, for the economic life of the pipeline, the users will ship sufficient volumes at the established tariff to enable the owners of the pipeline to repay their loan, meet the operating and maintenance costs and return a profit to compensate them for their risk and warrant the investment.

In the case of an oil find, geologists need to confirm the significance of the oil find, estimate the reserves and determine production capacity. These activities form the basis for estimating 
expected throughput. Petroleum industry specialists study potential markets and the value of future production. They forecast conditions that may affect the pipeline, directly or indirectly, over the next 15 to 20 years. These include the state of the economy; shifts in population; product demand growth; refinery construction; expansions and shutdowns; domestic and foreign crude-oil production; prospects for competitive pipelines; industry changes; and government actions.

\section{Facility site selection}

The type, layout, location, number and capacity of facilities are of strategic importance. The correct location of a facility may bring about lower total transport costs from the location of raw materials or primary producers through the supply chain to the consumer. The first consideration when selecting a site is the location of the firm's various resources and market areas.

The planning of a pipeline necessitates the investigation of several alternatives in order to determine whether the project is justified in terms of the resources its commercial existence will require (Adler, 1987). First, comparisons may have to be made with alternative locations for the pipeline. The shortest and most direct alignment between origin and destination might initially be preferred (for example, in the case of a crude-oil pipeline that delivers its entire payload to one destination). However, deviations may be necessary because of topographic obstructions and other environmental considerations, present land uses, difficulty in obtaining rights of way, and the need to pass near certain supply or delivery points or to skirt heavily populated areas (for example, in the case of a products pipeline that has delivery points along the route). Bearing in mind that the largest delivery point (or customer) is usually the one at the end of the line, the route alignment should not be located so circuitously that it unnecessarily puts the customer(s) at the end of the line at a distance and tariff disadvantage in favour of intermediate delivery points/customers. In this case, the economic trade-off is between a circuitously located pipeline and one with a direct alignment, but with small lateral branch delivery lines along the way. This economy means that the total quantity handled must be sufficient to keep the pipeline full. A prerequisite for successful pipeline transport is the correct sizing of the pipeline for the quantity of commodity that it will carry.

A second consideration is the size of the pipeline. One with a larger diameter, able to handle a greater traffic volume, involves a higher initial investment cost but lower costs for pumps and energy to propel the pumps.

A third important decision is whether the refinery should be located at the beginning of the line (upstream, close to the oil field or the port of entry) or at the end of the line (downstream, close to the market). The greater the viscosity and density of the commodity to be carried, 
the more difficult it is to pump and, therefore, the higher the cost. Crude oil, for example, is substantially more expensive to carry over long distances than the lighter, more fluid petroleum products that are refined from it. The greater the volumes to be carried and the longer the distance, the more economical it may be to locate the refinery at the line's origin. Upstream refinery location also enables the provision of downstream delivery points along the line, which can improve the efficiency of product distribution.

\section{Procurement}

Procurement is the acquisition of goods, services and information to ensure the operating effectiveness of the firm's manufacturing and marketing processes. The procurement function includes 1) selecting resources and suppliers; 2) determining the form in which the inputs are to be acquired; 3 ) timing and coordinating the arrival of incoming goods; 4) price negotiation; and 5) quality control of incoming goods.

The choice of a specific pipe for a given project is determined by economic factors, the nature of the commodity, expected throughput, terrain and construction conditions. Since the late 1800s, steel has been the material of choice for virtually all pipelines and tanks. Nowadays, double submerged arc-welded pipe is used; it has a seamless spiral weld (which has replaced longitudinal welding) as strong as the pipe itself (Moller, 2008).

Quality control through inspection is conducted throughout the materials-procurement and construction process. The pipe is checked for obstructions; proper placement of the seams is confirmed; the welds are inspected and tested; and the coatings are examined. Every part of the pipeline must meet the safety standards required by government regulations and the quality criteria of the industry (Rabinow, 2004).

\section{Materials-handling}

Materials-handling is concerned with every aspect of the (off-road) movement or flow of raw materials, semi-finished goods and finished goods on site. Successful materials-handling contributes to reducing inventory, lowering costs and increasing productivity.

Because cost is incurred without adding value each time goods are handled at a terminal or storage facility, a primary logistics objective is to eliminate handling wherever possible. With the carriage of crude oil and petroleum products by pipeline this objective is fully met. Commodity intake, haulage and discharge are combined in one process, usually a remotecontrolled operation.

\section{Packaging}

From a logistics perspective, packaging serves a dual role. First, the package protects the product from damage and may prevent a product from damaging other goods because 
of any hazards it potentially possesses. Second, packaging can make it easier to store and move products by reducing handling, thereby lowering materials-handling and distribution costs.

A commodity that is transported by pipeline to its destination requires no packaging. Only the commodity itself moves; the pipeline provides the necessary containment and protection of the commodity. Therefore, there is no dunnage dead weight, dunnage volume, vehicle or handling equipment moved. Furthermore, with pipeline transport there are no empty containers to be stored, handled or returned to the origin and no packing or unpacking problems at the start and completion of the haul.

\section{Warehouse management}

Goods must be stored for later sale and consumption unless customers need them immediately after production. Warehousing entails the activities that manage the space needed to hold or maintain inventories.

Warehouses for pipelines take the form of tank farms. Tank farms act, first, as receiving and central gathering points where shipment consolidation takes place; secondly, as storage facilities where buffering takes place; and, thirdly, as facilities where shipments are segregated for delivery. Tank farms are situated at oil fields, refineries, seaports, pumping stations and wholesale depots. The main function of tank farms is to act as buffers in which commodities that arrive out of synch with their demand can be stored until needed. At oil fields they receive crude oil from gathering systems and feed it into the trunk line. Along the trunk line, tank farms are used to sidetrack and consolidate crude oil in transit temporarily for batching, measuring, rerouting or holding during pipeline repairs. At the pipeline terminal, the various crude-oil shipments are again segregated into tanks for delivery to other pipelines, refineries or seaports.

In petroleum-importing countries, such as South Africa, large oil terminals are located at selected seaports of entry. Ocean-faring ships do not observe strict schedules, and irregular arrivals occur for a variety of reasons. On some days, no ships will arrive, whereas on others several crude-oil-carrying ships may arrive together. Refineries kilometres away may be working at a steady pace. The pipelines themselves vary in size. Pipes with a large diameter are used to unload ships rapidly and transport the crude oil to the tank farms at the seaports. On the exit side of the tank farms, smaller-capacity pipes distribute the crude oil in a steady stream to the refineries. Supplies for the refineries must be available even at times when ships do not come in or reception otherwise does not take place. Conversely, when several ships arrive simultaneously the terminal must have sufficient buffer storage capacity to unload the ships and turn them around. 


\section{Inventory management}

Inventory management is a critical issue. The needs of both the manufacturing and marketing functions have to be met continuously. However, large volumes of inventory occupy capital-intensive warehouse space; furthermore, possession of the inventory itself drains financial resources. The cost of warehouse space and the value of the inventory both have an opportunity cost. Consequently, an optimal trade-off must be reached between this opportunity cost and the harmful effects that would result from a stock-out situation.

Sophisticated computer monitoring of facilities combined with insignificant environmental influence mean minimal loss and damage to inventory (for instance, leaks can be quickly detected) and very reliable delivery schedules. The only negative characteristic is the slow service, which, ironically, has positive implications: the high accuracy and reliability of forecasted delivery times diminish the need for safety stock at the receiving end; and, in essence, pipelines offer free storage for as long as the order is on the way to delivery (Papacostas \& Prevedouros, 2001).

\section{Order processing}

Order processing encompasses the activities associated with filling customers' orders. These include:

- transmitting order details to the sales section

- verifying consumers' creditworthiness

- transmitting the consignment's required packaging details to inventory-control staff for delivery to the dispatch section

- preparation of the shipment documentation

- communicating the order status, method of payment and delivery details to customers.

The key to efficient pipeline operations is scheduling. This requires programming each shipment from origin to destination within the trunk pipeline so that the entire stream moves smoothly and at a desired rate all the time. For this purpose, schedulers canvass all potential shippers for their supplies, sales, purchases and requirements. They then develop the monthly pipeline pumping rates, and apportion capacity among shippers if more crude is tendered than the pipeline can carry (Trench \& Miesner, 2006).

\section{Logistics communications}

Successful logistics usually requires the effective management of information and communications systems. Effective communication must take place between 1) the firm and its customers; 2) the firm and its suppliers; 3) the major functional components of the firm - for example, marketing, manufacturing and logistics; 4) the various logistics activities, such as procurement, warehousing, order processing, inventory control and transport; and 5 ) the various components of each logistics activity. Accurate and timely communication is the cornerstone of successfully integrated and coordinated logistics management. 
In addition to the physical features - pipe, pumps, and tanks - the pipeline's basic design includes control centres utilising modern computer systems, communications equipment, and other electronic control mechanisms. Linking the system together through electronic, telephone and radio communication, these controls maintain a high degree of automation, cost and time savings, and built-in safeguards. Collectively these technologies permit a few people in a central location to continuously keep the entire system operating safely, efficiently and effectively. These technologies also permit rapid and accurate pipeline accounting.

Pipeline operations controllers (called dispatchers) using computers remotely control the pumps and other aspects of pipeline operations. Pipeline control rooms utilise Supervisory Control and Data Acquisition (SCADA) systems that return real-time information about the rate of flow, pressure, speed, and other information that is important to product quality maintenance, for example, the specific gravity, flash point, temperature and density of the commodity being pumped. Operations control staff, utilising diagnostic computer aids, monitor and evaluate the information continuously throughout a year to ensure an uninterrupted and desired commodity flow rate (Allegro Energy Group, 2001).

\section{Transport}

In its simplest form, pipeline transport takes place by pumping a commodity through a pipe from an origin where the commodity is in surplus to a destination where it is needed.

A consignment of crude oil through a pipeline in an oil-producing area usually follows this process: it is pumped out of an oil well or borehole into separator tanks where natural gas is diverted to another system. The crude oil then flows into heat treaters where water and sediments are removed, and then into 'lease tanks' where it is held until the required volume is ready for delivery to the pipeline gathering system (Leonard, 1982).

When a shipper's crude oil enters the trunk line, it joins other shippers' crude oil. The various crude-oil volumes are batched according to grade. The pipeline operator delivers approximately the same quantity of comparable oil to the destination as received from the producer. Equal grades of crude oil are fungible, which means that a given volume for one shipment may be substituted for the same volume from any other shipment.

Dispatchers control the operations of the entire trunk pipeline system from a single control room. They can start, accelerate, decelerate and stop pump activity at stations hundreds of kilometres away, and monitor pressures, flow rates and density. Dispatchers are able to switch streams from one delivery point to another.

\section{Reverse logistics}

The handling of return goods is an integral part of the logistics process. Customers may return goods to the seller because of defects, excesses or the wrong items being received. 
Often, logistics systems are not established to manage, or are incapable of handling, goods movement on return or contra-flow trips.

Pipeline transport is a non-containerised bulk mode of transport, thereby obviating the need for packaging and the returning of empty containers. Pipelines provide a direct and long-term link between origins and destinations. If necessary, a continuous service can be provided with no need for a return trip or a reverse pumping process. The lack of a need for reverse logistics activities contributes substantially to the high measure of economies of scale that pipeline transport enjoys.

\section{RELATIVE EFFICIENCY OF PIPELINE OPERATIONS}

Pipeline infrastructure is highly capital-intensive. However, once constructed, the remaining operating costs incurred to supply service are relatively small. Continuous-flow pipeline transport replaces batch haulage (i.e. separate vehicle loads) by other modes with an uninterrupted, high-volume operation. Owing to the high returns that result from economies of scale and density, which can be achieved when demand is sufficient and enduring to allow for continuous high utilisation, pipeline transport is very competitive in comparison with other forms of land transport. For example, the comparative 2008/09 tariffs for delivering jet fuel from Durban to O.R. Tambo International Airport in Gauteng (704 km) were as follows (Africon, 2008):

- Pipeline: $12.55 \mathrm{c} / \mathrm{l}$

- Rail: $24.35 \mathrm{c} / \mathrm{l}$

- Road: $58.30 \mathrm{c} / \mathrm{l}$

It is clear, therefore, that a Durban-based petroleum wholesaler that does not have access to pipeline or rail transport between Durban and Gauteng is subject to the risk of not being able to market its product(s) in Gauteng through competitive foreclosure (Competition Commission of South Africa, 2005).

At an operating speed of $10 \mathrm{~km} / \mathrm{h}$ the proposed $60-\mathrm{cm}$ Transnet pipeline would be able to deliver 3.54 million litres of petroleum product per hour. This is equivalent to 89 deliveries per hour using road tank vehicles with an average carrying capacity of 40000 litres of fuel per vehicle. This pipeline throughput is also equivalent to two trains departing per hour, each consisting of 42 petroleum tank wagons with an average carrying capacity of 42500 litres of fuel per wagon. Considering that such road trucks and rail wagons return empty to the upstream refineries in Durban, it is clear that there is no tenable long-term alternative to pipeline transport. Pienaar and Botes (2005) estimated the petroleum commodity throughput capacity of the major rail and road links between Durban and Gauteng, under the prevailing shared right-of-way and traffic conditions, at respectively 1.0 and 0.8 million litres per hour. 
The relative economy of pipeline transport as an alternative to other forms of transport derives from the following factors (Allegro Energy Group, 2001; Rabinow, 2004; Bardi, Coyle \& Novack, 2006; Trench \& Miesner, 2006; Pienaar \& Vogt, 2009):

1) Pipelines are able to move voluminous batches of fluids uninterruptedly in a continuous stream over long distances at a low unit cost and with low risk. Even when different grades of oil are to be batched, a continuous flow is maintained with very little mixing. Depending on the material, the intermix oil at the interface is put in a tank of the lower-valued grade. State-of-the-art pipeline pigs, which are equipped with remote sensing devices, can be used, first, to help separate consecutive batches with unusual qualities that cannot be mixed (thereby reducing commodity intermixing and dilution); secondly, to clean a pipe's wall (thereby keeping the entire volume of the pipe available to accommodate payload and keeping the wall smooth, which enhances commodity flow); and, thirdly, to detect at an early stage the formation of flaws and wear (thereby avoiding potential costly repairs and loss of income through downtime).

2) A commodity transported by pipeline to its destination requires no packaging. Only the commodity itself moves; the pipeline provides the necessary containment and protection of the commodity. Therefore, there is no dunnage dead weight, dunnage volume, vehicle or handling equipment moved. Furthermore, with pipeline transport there are no empty containers to be stored, handled or returned to the origin and no packing or unpacking problems at the start and completion of the haul.

3) Among all transport modes, pipelines consume the least energy per unit of commodity moved. To deliver the same quantity of commodity, the fuel consumption of road tank vehicles is several hundred times higher than that of a pipeline, and that of rail tank vehicles between 30 and 50 times higher than that of a pipeline (Africon, 2008).

4) Pipelines are the safest mode of transport for carrying petroleum commodities. There is a notably small number of deaths and injuries associated with pipeline operations. The high degree of automation throughout pipeline systems accounts to a large extent for their outstanding safety record. Per unit carried it requires the least human-resource effort, and pipeline traffic does not share right of way with other users.

5) Pipeline transport benefits from an outstanding record of goods security. Lately, there has been a technological development in processing the intermix that develops between consecutive batches. Pipeline operators can now install refractionators at major pump stations to re-refine the intermixed fuel back into its constituent products (e.g. petrol of a certain grade and diesel), which obviates the need to blend the mixture into a following batch, or to return it to the refinery.

6) Large areas of land are not diverted to exclusive use. The area required is a narrow ribbon, and diversion of land from other uses is lessened if the pipes are buried beneath the surface of the ground (as they usually are).

7) Once the problems of location and construction have been overcome, pipeline systems incur the lowest external cost, cause least ecological damage and have the smallest carbon footprint of all modes of transport. 
8) The high accuracy and reliability of forecasted delivery times diminish the need for safety stock at the receiving end, while free storage is offered for as long as the order is on the way to delivery. Because cost is incurred without adding value each time goods are handled at a terminal or storage facility, a primary logistics objective is to eliminate handling wherever possible. With the carriage of crude oil and petroleum products by pipeline this objective is fully met. Commodity intake, haulage and discharge are combined in one process, which is usually a remote-controlled operation.

\section{SERVICE EFFECTIVENESS}

The most pertinent freight transport service performance determinants demanded by customers are suitability, accessibility, goods security, transit time, reliability and flexibility. Below, each of these determinants is briefly defined generically, followed by a pipelinespecific elucidation.

Suitability refers to the technical ability of a carrier to provide the equipment and facilities required for transporting a particular commodity.

Pipelines require a high investment cost. This cost is fixed (i.e. unavoidable) and it rises rapidly per unit when throughput falls. Therefore, pipeline transport is not suitable for businesses that need small product volumes on an irregular basis.

Accessibility is the ability of a carrier to provide service across a particular link and to physically gain access to facilities. More specifically, it is the ability to move goods from a designated point of origin to a desired point of use or consumption.

Pipeline transport (in the case of petroleum commodities) can provide a tank farm-to-tank farm service only. Tank farms are situated at oil wells, refineries, seaports, pipeline terminals and wholesale depots. Therefore, pipeline transport can provide a fully accessible service upstream between wholesale depots and a petroleum refinery. Downstream from depots, pipelines supply zero accessibility. Consequently, the distribution of petroleum products from the depot to the customer is conducted almost without exception by road transport (see Figure 1).

Goods security means that goods should arrive in the same quantity and quality (i.e. physical condition) as when tendered to the carrier.

As far as quantity goes, the goods security record of pipeline transport is outstanding. The risks of shrinkage or loss by theft, fire, damage, spillage and evaporation are insignificant. The electronic monitoring of facilities and insignificant influence of the elements result in minimal loss and damage (through quick detection of leaks) and in highly reliable delivery 
schedules. In the United States, average commodity spillage is estimated to be approximately one US gallon per million barrel-miles (Rabinow, 2004).

As for quality, lately there has been a technological development in processing the intermix that develops between consecutive batches. Pipeline operators can now install refractionators at major pump stations to re-refine the intermixed fuel back into its constituent products (e.g. petrol of a certain grade and diesel), which obviates the need to blend the mixture into a following batch. From 2011 onwards all petroleum- products pipelines in South Africa will have to be equipped with refractionators (NERSA, 2007).

Order lead time (or order cycle time) is the total time that elapses between order placement and delivery. It is often assumed that the higher the speed, the higher the transport cost. In logistical terms, speed means short replenishment and delivery cycles, and consequently less stock within the system.

On a crude-oil trunk or long-distance delivery pipeline, a shipper (whenever he is not the only shipper) has to indicate his batch size beforehand when requesting shipment capacity. The waiting time or notice period for dispatch of a shipment that is carried in batch mode varies between 14 and 28 days. When shipment takes place in fungible mode, shippers usually make capacity available from between 48 hours and 14 days (Lund, 2002).

Although the transit speed is low (between 5 and $15 \mathrm{~km} / \mathrm{h}$ ), commodity intake, carriage and discharge are combined in one process - the commodity is immediately discharged into storage tanks upon arrival. This, coupled with the fact that the pumping process can take place continuously, without the need for a return journey or empty running, stoppages or transhipment delays, reduces the total transit time.

Reliability refers to the consistency of the transit time provided by a carrier. It reflects the record or reputation for consistently maintaining punctual performance in terms of prearranged collection and delivery times of goods in the same condition and quantity as tendered to the carrier.

Pipeline transport is highly reliable because it is both secure and punctual. The reasons for this are as follows:

- Pipelines are not labour-intensive; they are largely automated and only a few employees are needed to control pumps and valves, or to undertake maintenance. Worker strikes and absenteeism have relatively little effect on their operations.

- Commodity flows through pipelines are electronically monitored and controlled. This enables the quick detection of leakages. Losses due to pipeline leaks or damage are extremely rare.

- Inclement weather conditions do not disrupt service. 
Flexibility is the proven ability, readiness and willingness to effectively handle variations in load volumes, load mass, collection and delivery times and locations without any significant loss in overall efficiency. Flexibility supports reliability when the transport operator is able to accommodate supply disruptions, schedule deviations, expedite the progress of a consignment and alter collections and deliveries.

Once established, a pipeline is inflexible in two ways: with regard to geography and with regard to use.

- Pipelines are geographically inflexible because they are designed to serve fixed locations.

- The use of a pipeline is inflexible in that the commodity to be carried can only be varied within limits of compatibility. For example, within the range of petroleum products, it does no harm to vary the product from aviation fuel to petrol or diesel. However, it cannot be varied from a petroleum product to a beverage or another potable liquid.

Synthesis: Suitability and accessibility determine whether a carrier and its available technology are capable of physically performing the desired services. Goods security, shorter and more reliable transit times and greater service flexibility are sources of competitive advantage. Shorter transit times, higher reliability and greater flexibility lead to lower inventory levels and stock-out costs.

A service ranking of the three modes of transport used for carrying petroleum commodities over long distances on land is given in Table I.

Table I: Service comparison of transport modes used for the carriage of petroleum commodities over long distances on land

(Source: Pienaar, 2010b)

\begin{tabular}{|l|c|c|c|}
\hline Service characteristics & \multicolumn{3}{|c|}{ Relative performance in general terms } \\
\hline Suitability & Highest & Rail & Rowest \\
\hline Accessibility & Pipe & Rail & Pipe \\
\hline Goods security & Road & Road & Rail \\
\hline Journey speed & Pipe & Rail & Pipe \\
\hline Reliability & Road & Road & Rail \\
\hline Flexibility & Pipe & Rail & Pipe \\
\hline
\end{tabular}




\section{CONCLUSION AND POLICY RECOMMENDATION}

Owing to high levels of efficiency, which are achievable when demand is sufficient and enduring to allow for continued high utilisation, pipeline transport is very competitive compared to other modes of land transport. For example, between Durban and Gauteng pipeline tariffs per litre of fuel are approximately half of the rail tariffs and one-fifth of the road transport tariffs. The throughput capacity of pipelines cannot be matched by other modes of land transport. For example, between Durban and Gauteng the throughput capacities of the main rail and road links are approximately one-fifth and one-quarter respectively of the throughput capacity of the new 60-cm Transnet pipeline.

Access to pipelines is limited because of their fixed right of way. Shippers whose facilities are not connected to a pipeline must use another accessible mode of transport. Petroleum pipeline transport provides a tank farm-to-tank farm service. Tank farms are situated at oil wells, refineries, seaports, pipeline terminals and wholesale depots. Therefore, pipeline transport can provide a fully accessible service upstream between wholesale depots and a petroleum refinery. Downstream from depots, pipelines supply zero accessibility. Although the transit speed is low, the high accuracy and reliability of forecasted delivery times diminish the need for safety stock at the receiving end, and free storage is offered for as long as the order is on the way to delivery.

For businesses that need large product volumes on a regular basis and whose facilities are connected to a pipeline, and who by implication then also have tank storage at their disposal, pipeline transport is the most effective form of transport. Full access to a pipeline under such conditions renders pipeline transport the most suitable mode of transport, owing to its superior reliability and outstanding goods security.

Due to the fact that pipeline transport 1) is substantially cheaper than road and rail transport; 2) frees up alternative road and rail vehicle fleet and infrastructure capacity; 3 ) is the most energy-efficient mode of land transport; and 4) is much safer than other modes of land transport, pipeline transport should, subject to economic assessment and financial appraisal, be considered as the preferred mode of transport to all major petroleum tank farms. 


\section{REFERENCES}

Adler, H. A. 1987. Economic appraisal of transport projects. Baltimore: The Johns Hopkins University Press.

Africon. 2008. Study on the macro-economic impact of fuel costs in transport. Contract report produced for the National Department of Transport. Pretoria.

Allegro Energy Group. 2001. How pipelines make the oil market work - Their networks, operation and regulation. A memorandum prepared for the Association of Oil Pipe Lines and the American Petroleum Institute's Pipeline Committee. Available from: http://www. aopl.org/about/pipelines.html (accessed 18 May 2010).

Ballou, R. H. 2004. Business logistics/supply chain management (5th edition). Upper Saddle River: Pearson Prentice Hall.

Bardi, E. J., Coyle, J. J. \& Novack, R. A. 2006. Management of transportation. Mason: South-Western.

Bowersox, D. J., Closs, D. J. \& Cooper, M. B. 2007. Supply chain logistics management (2nd edition). New York: McGraw-Hill.

Competition Commission of South Africa. 2005. Competition Commission recommends approval of the 'Uhambo' joint venture. Media Release number 10 of 2005 (12 May). Pretoria.

Council of Supply Chain Management Professionals. 2010. Supply chain management/ Logistics management definitions. Available from: http://www.cscmp.org/ (accessed 26 May 2010).

Grant, D. B., Lambert, D. M., Stock, J. R. \& Ellram, L. M. 2006. The fundamentals of logistics management (European edition). Berkshire: McGraw-Hill.

Leonard, V. K. 1982. Petroleum pipelines. In Homburger, W.S. (ed.). Transportation and traffic engineering handbook (2nd edition). Institute of Transportation Engineers, Englewood Cliffs: Prentice Hall, pp. 101-13.

Lund, G. 2002. Senior manager: Operations, Petronet. Private communication on 9 July 2002.

Moller, C. 2008. Chief executive: Transnet pipelines. Private communication on 7 October 2008. 
Murphy, P. R. \& Wood, D. F. 2004. Contemporary logistics (8th edition). Upper Saddle River: Pearson Prentice Hall.

NERSA (National Energy Regulator of South Africa). 2007. Licence condition relating to tariffs of a petroleum pipeline system including storage facilities. 29 March 2007. Available from: http://www.dme.gov.za (accessed 2 June 2008).

Papacostas, C. S. \& Prevedouros, P. D. 2001. Transportation engineering and planning (3rd edition). Englewood Cliffs: Prentice-Hall.

Petroline. 2008. Environmental impact assessment for Petroline RSA (Pty) Ltd for a proposed liquid fuels pipeline from Komatipoort to Kendal and a liquid fuel storage facility near Nelspruit. Available from: http://www.petroline.co.za (accessed 14 October 2008).

PetroSA. 2008. PetroSA increases the capacity of its planned Coega crude refinery. Available from: http://www.petrosa.co.za (accessed 27 October 2008).

Pienaar, W. J. 1998. Report to Petronet on the development of a defensible pricing mechanism. Contract report produced for Petronet. Stellenbosch: Department of Logistics, Stellenbosch University.

Pienaar, W. J. 2010a. The regulation of commercial petroleum pipeline operations: A South African example. Corporate Ownership \& Control, 7(3): 188-92.

Pienaar, W. J. 2010b. Logistics management aspects of planning, implementing and controlling commercial petroleum pipeline operations. Corporate Ownership \& Control, $8(1) ; 1-10$.

Pienaar, W. J. \& Botes, F. J. 2005. View on the road and rail constraints to transport petroleum products to the inland market. Contract report produced for British Petroleum (South Africa). Cape Town.

Pienaar, W. J. \& Vogt, J. J. 2009. Business logistics management: a supply chain perspective (3rd edition). Cape Town: Oxford University Press.

Porter, M. E. 1984. Competitive advantage: Creating and sustaining superior performance. New York: The Free Press.

Rabinow, R. A. 2004. The liquid pipeline industry in the United States: Where it's been, where it's going. A report prepared for the Association of Oil Pipe Lines. Available from: http://www.aopl.org/about/pipelines.html (accessed 2 June 2008). 
Schumer, L. A. 1974. Elements of transport (3rd edition). Sydney: Butterworths.

Trench, C. J. \& Miesner, T. O. 2006. The role of energy pipelines and research in the United States: Sustaining the viability and productivity of a national asset. Pipeline Research Council International. Available from: http://www.aopl.org/about/pipelines.html (accessed 2 June 2008). 